\title{
Prevalence and Predictors of Non-Uptake of HIV Voluntary Counseling and Testing among Undergraduates of Tertiary Institution in Abia State, Nigeria
}

\author{
Prince Ezenwa N. Onyemachi' ${ }^{1}$, Madu James Awa ${ }^{2 *}$, Mazi E. C. Ejikem ${ }^{3}$, Juliet U. Enukeme ${ }^{1}$ \\ ${ }^{1}$ Department of Community Medicine, Abia State University Teaching Hospital, Aba, Abia State, Nigeria \\ ${ }^{2}$ Department of Community Medicine, College of Medicine and Health Sciences, Gregory University Uturu, Abia State, \\ Nigeria \\ ${ }^{3}$ Department of Obstetrics and Gynaecology, Abia State University Teaching Hospital, Aba, Abia State, Nigeria \\ Email: *maduawa2000@yahoo.com
}

How to cite this paper: Onyemachi, P.E.N., Awa, M.J., Ejikem, M.E.C. and Enukeme, J.U. (2021) Prevalence and Predictors of Non-Uptake of HIV Voluntary Counseling and Testing among Undergraduates of Tertiary Institution in Abia State, Nigeria. Open Journal of Statistics, 11, 19-35.

https://doi.org/10.4236/ojs.2021.111002

Received: October 20, 2020

Accepted: January 10, 2021

Published: January 13, 2021

Copyright $\odot 2021$ by author(s) and Scientific Research Publishing Inc. This work is licensed under the Creative Commons Attribution International License (CC BY 4.0).

http://creativecommons.org/licenses/by/4.0/

\section{(c) (i) Open Access}

\begin{abstract}
Background: One of the key strategies in the HIV/AIDS prevention and control programs in Nigeria is Voluntary HIV counseling and testing (VCT). However, its utilization among young adults, particularly undergraduates, is very low. The aim of the present study was to determine the prevalence and predictors of non-uptake of VCT among undergraduates. Methods: A cross sectional study using quantitative methods was conducted. Using simple random sampling, three faculties were selected out of nine and 422 respondents were selected from three faculties. Interviews were conducted using pre-tested semi-structured questionnaires. Data analysis was done using statistical package for social sciences version 20. Prevalence was measured by the percentage of respondents that had never used VCT. Analytical statistics were done using chi-square test to measure strength of association between VCT uptake and knowledge and attitude of respondents. Association with P-value $<0.05$ was considered significant. Logistic regression was used to identify predictors of non-uptake of VCT. The associations were presented as odds ratios (OR) and 95\% confidence intervals. Results: Overall, 59.3\% of respondents were knowledgeable about VCT while majority, $64.7 \%$ had negative attitude towards it. Knowledge $\left(\mathrm{X}^{2}=9.89, \mathrm{P}\right.$-value $\left.<0.001\right)$ and attitude $\left(\mathrm{X}^{2}=\right.$ $10.78, \mathrm{P}$-value $<0.001)$ showed statistically significant association with VCT uptake. The prevalence of non-uptake of VCT among the respondents was $82.7 \%$. Ignorance, fear of positive test, stigma and discrimination were found to be strong predictors of non-uptake of VCT. OR 1.874 (1.058 - 3.289), P <
\end{abstract}


0.001 ; OR 2.455 (1.308 - 4.608), $\mathrm{P}<0.000$ and OR 2.318 (1.299 - 4.128), $\mathrm{P}<$ 0.000 respectively. Conclusions: VCT uptake among undergraduates was low and determined by VCT-related ignorance, poor attitude, fear of positive result and HIV/AIDS-related stigma/discrimination. In order to change the narrative, HIV/AIDS prevention and control programs in Nigeria should address the identified predictors of non-VCT uptake. There is a need to focus on young adults when designing, expanding and implementing VCT services in the country.

\section{Keywords}

Prevalence, Predictors, VCT Non-Uptake, Tertiary Institution, Abia State

\section{Introduction}

It was estimated that there were 38 million people living with HIV/AIDS globally at the end of 2019 with an estimated 1.7 million new infections, declining by $23 \%$ from 2010 value of 2.1 million. Young people aged 10 - 24 years accounted for over $50 \%$ of all HIV cases globally. It was further estimated that 690,000 people died from AIDS-related illnesses at the end of 2019 worldwide, down by $39 \%$ from 2010 value of 1.1 million. As of the end of June, 2020, 26 million people were accessing antiretroviral therapy [1].

Sub-Southern Africa is the region hardest hit by HIV. It is home to around $6.2 \%$ of the world's population but over half $(54 \%)$ of the total number of people living with HIV in the world. In 2018, there were 800,000 new HIV infections, just under half of the global total [2]. Around 310,000 people died of AIDS-related illnesses in the region in 2018 , although the number of deaths has fallen by $44 \%$ since 2010 [3]. Of the 19.6 million adults living with HIV in the region in 2019, 12 million were women and 7.6 million men. Young women aged 15 - 24 years accounted for $26 \%$ of new HIV infections in 2019, despite making up around $10 \%$ of the population.

In 2019, Nigeria was fourth in the global burden of HIV/AIDS with an estimated 1.9 million people living with HIV and had one of the highest rates of new infections in sub-Saharan Africa (130,000) [4]. There were estimated 53,000 AIDS-related deaths same year with estimated annual prevalence of $1.4 \%$ [5]. Although HIV prevalence among adults is much less (1.4\%) than other sub-Saharan African countries such as South Africa (19\%) and Zambia (11.5\%), the size of Nigeria's population means that a large number of people were living with HIV in 2019. Recent drops in prevalence estimates for the country has been attributed to better surveillance [6].

Nevertheless, UNAIDS estimates that around two-thirds of new HIV infections in West and Central Africa in 2019 occurred in Nigeria. Together with South Africa and Uganda, the country accounts for around half of all new HIV infections in sub-Saharan Africa every year [7]. This is despite achieving a $13 \%$ 
reduction in new infections between 2010 and 2019. HIV prevalence is the highest in Nigeria's southern states (known as the South-south Zone), with 5.5\% and the lowest in the southeast (the South East Zone) with a prevalence of $1.8 \%$. There are higher rates of HIV in rural areas (4\%) than in urban ones (3\%) [8].

Young people aged 15 - 24 years are at the highest risk for HIV/AIDS epidemic in Nigeria [9]. They are vulnerable to HIV because of the strong influence of peer pressure and the development of their sexual and social identities. This age group with estimated HIV prevalence of $3.5 \%$ is the highest among countries in West and Central Africa [10]. The epidemic is driven by this age group in the matrix of low risk perception, risky sexual behavior, low condom use, lack of knowledge and access to appropriate reproductive health services [11]. In Nigeria, HIV/AIDS is further aggravated by inadequate sexual health education, inadequate voluntary HIV testing and counseling, unhealthy cultural practices and poor health care system, especially in the secondary and tertiary institutions [12].

In recent years, a number of countries in the sub-Saharan Africa have implemented national campaigns to encourage uptake of HIV testing and counseling. In 2018, 85\% of people living with HIV had knowledge about their status-a significant improvement from 77\% in 2015 and higher than the global percentage in 2018 (79\%) [13] [14]. Despite their high risk for HIV infection, VCT uptake by young people is significantly lower [15]. According to sub-Saharan Africa survey (2005-2010), only $10 \%$ of males and $15 \%$ of females between the ages 15 - 24 years knew their HIV status, an indication that the majority were undiagnosed, thus enhancing their risk of either being infected or transmitting the disease [15].

In 2004, Nigeria commenced Voluntary Counseling and Testing following the establishment of The National Agency for the Control of AIDS (NACA), in February 2000 to coordinate the various activities of HIV/AIDS in the country [16]. Voluntary counseling and testing are internationally recognized as an effective and important strategy for both prevention and care of HIV [17].

It can be defined as a confidential face-to-face interaction between a professional counselor and a client or a group of clients with a view to assisting the clients to make informed decisions and adjust effectively in life [18]. Several authors have noted that VCT is a key element to identifying HIV-infected persons who could benefit from therapeutic interventions [19] [20]. However, there is a dearth of VCT services in Nigeria, and even where they are available, uptake has been reportedly low [21].

In 2018, 34\% of adults living with HIV were aware of their status [22]. Across the country testing rates are low: only $15.1 \%$ of people between the ages of 15 24 had been tested in the last 12 months and knew their results. The low uptake of VCT among young people is believed to be associated with different factors, ranging from fear of knowing their HIV status to the limiting factors towards the service and social issues influencing the attitudes and behaviors of the service 
providers [15]. Further, approximately $50 \%$ increase of AIDS-related deaths among adolescents between 2006 and 2016 was associated with inadequate youth friendly VCT services, poor prioritization of adolescent issues, inadequate treatment and lack of support to the young people [23].

The 2016 Nigeria National HIV Strategy for Adolescents and Young People recognized negative provider attitudes towards young people and their sexual activities, limited access to youth-friendly services, low awareness of HIV and fear of stigma and discrimination as being key challenges preventing young people from taking up sexual health services such as VCT [24]. Studies in different areas indicated that knowledge, attitude and practice of tertiary school students towards VCT is low and its uptake is minimal [24]. Major hindrances to uptake of VCT for HIV are associated with ignorance, fear of being positive, cost of VCT, inadequate number of VCT centers and stigmatization [17] [25] [26] [27] [28]. Nigeria aims to reach the UNAIDS target, with $90 \%$ of people living with HIV knowing their status by 2021 [29].

Regardless of high awareness, knowledge and potential benefits of VCT services, there is dearth of studies on the uptake of VCT services among students in tertiary institutions in the study area. Many potent interventions for HIV prevention such as creating awareness about VCT at community levels, targeting general population may be inappropriate for University students. The University community is an enabling environment for high-risk practices and behaviors, particularly unsafe sex [30]. This age group has a penchant for sexual adventure, often with multiple partners and inconsistent condom use [31] [32]. However, this is the most productive segment of the population that forms the basic education sector which is vital to the creation of human capital and sustainable economic development of the nation [33]. This study, therefore, aimed at assessing the prevalence and predictors of non-uptake of VCT services among students of tertiary institution in Abia Sate, South East, Nigeria, in order to facilitate the designing of appropriate strategies by the government and policy makers to improve VCT acceptance and utilization among young people in Tertiary institutions.

\section{Methods}

\section{Study area, study design and study period}

Abia State University is one of the state owned universities, located in South East part of Nigeria. It was established in 1981 with two campuses and over 20,389 regular undergraduates during the study period. It has nine faculties and, depending on the discipline, offers three to six years programmes for first degree. This was a quantitative study using cross-section method, and was conducted among students of Abia State University from October to November, 2019.

\section{Study Population}

The regular third year undergraduates from Abia State University in randomly selected departments were the study population. 


\section{Inclusion and Exclusion Criteria}

All regular third year undergraduates of the university were eligible to be included in this study. Students in nonregular courses and outside third year were not included in the study for reasons that they were different from the eligible ones with respect to their age, maturity, and exposure to the study subject.

\section{Sample size determination and sampling technique}

A single proportion formula was used to determine the sample size as there was no similar study in target group in our study area [11].

$$
n=\frac{p q}{(E / K)^{2}}
$$

where: $n=$ the required sample size.

$k=$ A constant; (1.96) approx. 2.0 at 95 percent confidence level).

$p=50 \%$ (prevalence of adherence gotten from previous adherence studies) (0.5) $[5]$.

$q=1.0-p=0.5$.

$E=$ Proportion of sampling error margin in a given situation of $5 \%$ i.e. 0.05 , giving a sample size of 384 . Ten percent adjustment was made to allow for non-response, bringing the sample size to 422 .

Multistage sampling technique was used to select the study participants from the target population. This technique was preferred because of the difficulty of managing the large target student population. In the first stage, simple random sampling method was used to select one out of two universities in Abia state. In the second stage, simple random technique was also used to select three out of nine faculties. In the third stage, simple random method was used to select one department each from the three faculties. The lists of all third year students from the selected departments were obtained from the registrar's office. Third year students were preferred because of their year of study which would enable them know and have opinion about VCT services if they existed on campus. Based on this sampling frame which showed almost equal number of students in the three selected departments, the 422 questionnaires were divided among the three departments on almost equal proportion for random administration to the students.

\section{Data collection}

The data collection instrument was a self-administered questionnaire divided into four parts; socio-demographic characteristics of participants, knowledge of participants regarding VCT, their attitude towards VCT and level of uptake of VCT for HIV. While data on Knowledge and Attitude were respectively obtained from a five item questionnaire, level of uptake of VCT for HIV was assessed from a single question; "Have you ever used VCT service?" with dichotomous "Yes" or "No" answer.

The instrument was pre-tested in one of the non-participating departments among twenty students to evaluate its appropriateness and correct any possible flaws Vin the sequence of the questions. Alpha Cronbach was used to test the reliability of the instrument and a value of 0.85 for knowledge of VCT was ob- 
tained. Eligible participants who gave informed consent were interviewed by well-trained assistants on the different sections of the questionnaire.

\section{Measurements}

The dependent variable for this study was VCT utilization. This was measured by asking the question: "Have you ever used VCT services in the past?" with dichotomous response "yes or no". The independent variables included socio-demographic characteristics, HIV/AIDS-related knowledge, HIV/AIDS-related attitude, HIV/AIDS-related stigma/discrimination towards people living with HIV/ AIDS, HIV/AIDS-related ignorance and VCT-related fear of positive result.

\section{Scoring}

The scores for knowledge and attitude were respective mean of the respondents' correct answers. Score greater than or equal to the mean was considered knowledgeable or having positive attitude. The prevalence rate of non-uptake of VCT was assessed by the percentage of respondents who answered "No" to the question on uptake of VCT service.

\section{Data management and analysis}

The data were checked for completeness; double entered and analyzed using SPSS-20 statistical software. The principal investigator also cross-checked the collected data for completeness, accuracy, clarity, and consistency throughout the data collection period. Descriptive statistics were used to describe frequency distribution of the variables. Chi square test was used to measure and test association between variables. A P-value $<0.05$ was considered to be statistically significant. Here, the dependent variable (uptake of VCT) is categorical with only two values "Yes" or "No", Logistic regression was therefore, used to assess the associations between the dependent and independent variables. In the regression models, information on ignorance of where to go for VCT, Fear of positive result, Fear of stigma/discrimination and Fear of people knowing my HIV status, were included as independent variables.

Collinearity among the independent variables was assessed by using a correlation matrix, and multicolinearity was not found. The associations were presented as odds ratios (OR) and $95 \%$ confidence intervals.

\section{Ethical consideration}

The research was approved by the ethical and research committee of the University. Informed consent was obtained from the study participants after explaining the objective of the research. To ensure confidentiality and no bias, the respondents were assured that the information provided would be used only for research purpose, so their identities were not taken and the interviewers also unknown to them.

\section{Results}

\section{Socio-demographic profile of respondents}

Table 1 shows the socio-demographic characteristics of the respondents. A total of 400 (94.8\%) out of 422 respondents enrolled for the study returned cor- 
rectly filled questionnaire. There were $222(55.5 \%)$ females. Their mean age was 23.5 years (SD 4.5 years). The majority, 348 (87.0\%), were unmarried and 380 (95.0\%) of Christian religion.

\section{Knowledge, attitude and uptake of VCT}

Knowledge about VCT

Table 2 shows participants' responses to knowledge questions about VCT with a mean score value of 2.96 . The majority, 237 (59.3\%) scored greater than

Table 1. Socio-demographic characteristics of the study subjects.

\begin{tabular}{cc}
\multicolumn{1}{c}{ Variables } & Frequency N (\%) \\
\hline 1. Age Group (Years) & $28(7.0)$ \\
$<20$ & $184(46.0)$ \\
$20-24$ & $57(14.2)$ \\
$25-29$ & $8(2.0)$ \\
$30-34$ & $2(0.5)$ \\
$\geq 35$ & $112(30.3)$ \\
Non-Response & \\
Mean age $=23.5$ SD4.5 & \\
2. Sex & $178(44.5)$ \\
Male & $222(55.5)$ \\
Female & \\
3. Marital Status & $52(13.0)$ \\
Married & $348(87.0)$ \\
Unmarried & \\
4. Religion & $380(95.0)$ \\
Christian & $2(0.5)$ \\
Muslim & $18(4.5)$ \\
Others & \\
\hline
\end{tabular}

Table 2. Participants' responses to knowledge questions about HIV/VCT.

\begin{tabular}{|c|c|c|}
\hline Questions & Responses & Freq. N (\%) \\
\hline \multirow{2}{*}{ 1. Are you aware of VCT } & Yes & $391(97.7 \%)$ \\
\hline & No & $9(2.3 \%)$ \\
\hline \multirow{2}{*}{ 2. Are you aware HIV testing is voluntarily } & Yes & $383(95.8 \%)$ \\
\hline & No & $17(4.2)$ \\
\hline \multirow{2}{*}{ 3. Ever heard about Counseling before HIV testing } & Yes & $150(37.5 \%)$ \\
\hline & No & $250(62.5 \%)$ \\
\hline \multirow{2}{*}{ 4. Ever seen VCT Service Center? } & Yes & $56(14.0 \%)$ \\
\hline & No & $344(86.0 \%)$ \\
\hline \multirow{2}{*}{ 5. Can VCT prevent and control HIV? } & Yes & $204(51.0 \%)$ \\
\hline & No & $196(49.0 \%)$ \\
\hline
\end{tabular}


or equal to the mean and were considered knowledgeable. The majority of respondents, 383 (95.8\%) knew that testing is voluntary, while minority, 150 (37.5\%) knew that counseling goes with HIV testing. Only 56 (14.0\%) respondents had ever seen a VCT center. Further, 204 (51.0\%) respondents knew that VCT can prevent and control HIV.

\section{Attitude towards VCT}

Table 3 shows the respondents' responses to attitude questions towards VCT. A five-item attitude questions towards VCT was used with "Yes" or "No" answer, giving an average mean score of 1.9. Less than half, 141 (35.3\%), of the respondents had positive attitude towards VCT service having scored higher than the mean score. Based on the findings, majority, 317 (79.3\%), of the respondents considered VCT necessary. Minorities, 138 (34.5\%) and 68 (17.0\%) of the respondents would like to take VCT services themselves and recommend it to friends respectively. While 118 (29.5\%) respondents admitted that the VCT site was conducive, a few, 64 (16.0\%), respondents admitted to having a choice of a counselor at the VCT site.

Uptake of VCT for HIV

Table 4 shows respondents' responses to uptake of VCT for HIV. Minority, $69(17.3 \%)$ respondents had used VCT service in the past. Hence, the prevalence of non-uptake of VCT among the respondents was $82.7 \%$. Among those who had used VCT, majority, 41 (59.4\%), of the respondents accessed the services in hospitals. For those who had never used VCT services, three major reasons given for non-uptake of VCT were, ignorance, 50 (15.1\%), fear of positive results, 105 (31.7\%) and fear of stigma and discrimination, 140 (42.3\%). In Table 5, knowledge about VCT $\left(\chi^{2}=9.89\right.$, P-value $\left.<0.001\right)$ and attitude towards VCT $\left(\chi^{2}=\right.$ $10.78, \mathrm{P}$-value $<0.001)$ showed statistically significant associations with the uptake of VCT for HIV.

Table 6 shows logistic regression analysis of the data. The dependent variable is non-uptake of VCT, while the independent (predictor) variables are ignorance,

Table 3. Participants' responses to Attitude questions towards HIV-VCT.

\begin{tabular}{|c|c|c|}
\hline Questions & Responses & Freq. $\mathbf{N}(\%)$ \\
\hline \multirow{2}{*}{ 1. Do you consider VCT necessary for students? } & Yes & $317(79.3 \%)$ \\
\hline & No & $83(20.7 \%)$ \\
\hline \multirow{2}{*}{ 2. Are you willing to take VCT? } & Yes & $138(34.5 \%)$ \\
\hline & No & $262(65.5 \%)$ \\
\hline \multirow{2}{*}{ 3. Would you recommend it to friends? } & Yes & $68(17.0 \%)$ \\
\hline & No & $332(83.0 \%)$ \\
\hline \multirow[b]{2}{*}{ 4. Is the VCT site conducive? } & Yes & $118(29.5 \%)$ \\
\hline & No & $282(70.5 \%)$ \\
\hline \multirow[b]{2}{*}{ 5. Do you have a choice of counselor at the VCT site? } & Yes & $64(16.0 \%)$ \\
\hline & No & $336(84.0 \%)$ \\
\hline
\end{tabular}


Table 4. Participants' responses to practice about HIV/VCT.

\begin{tabular}{|c|c|c|}
\hline Questions & Responses & Freq. $\mathbf{N}(\%)$ \\
\hline \multirow{2}{*}{$\begin{array}{l}\text { 1. Have you ever used VCT services in } \\
\text { the past? }\end{array}$} & Yes & $69(17.3 \%)$ \\
\hline & No & $331(82.7 \%)$ \\
\hline \multirow{5}{*}{$\begin{array}{l}\text { 2. If "Yes" where did you access VCT } \\
\text { Services? }\end{array}$} & Public Hospital & $41(59.4 \%)$ \\
\hline & School Medical Center & $4(5.8 \%)$ \\
\hline & Private Clinic & $21(30.4 \%)$ \\
\hline & Youth Center & $1(1.5 \%)$ \\
\hline & Medical Outreach & $2(2.9 \%)$ \\
\hline \multirow{5}{*}{$\begin{array}{l}\text { 3. If "No" what are your reasons for } \\
\text { not accessing VCT? }\end{array}$} & I have no idea where to go for it & $50(15.1 \%)$ \\
\hline & Fear of positive result & $105(31.7 \%)$ \\
\hline & Fear of stigma/discrimination & $140(42.3 \%)$ \\
\hline & Fear of people knowing my HIV status & $25(7.6 \%)$ \\
\hline & It is not within my reach & $11(3.3 \%)$ \\
\hline
\end{tabular}

Table 5. Association between Knowledge and attitude with uptake of VCT for HIV.

\begin{tabular}{cccc}
\hline Variables & $\begin{array}{c}\text { Uptake of VCT } \\
\text { Freq. N (\%) }\end{array}$ & $\begin{array}{c}\text { Non-uptake of } \\
\text { VCT Freq. N (\%) }\end{array}$ & X $^{2}$ P-Value \\
\hline $\begin{array}{c}\text { Knowledge on VCT } \\
\text { *nowledgeable }\end{array}$ & 157 & 81 & $9.89(0.001)^{\star}$ \\
${ }^{*}$ Not Knowledgeable & 56 & 106 & \\
$\begin{array}{c}\text { Attitude towards VCT } \\
{ }^{*} \text { Positive Attitude }\end{array}$ & 114 & 27 & $10.78(0.001)^{*}$ \\
${ }^{*}$ Negative Attitude & 18 & 241 &
\end{tabular}

*Statistically significant.

Table 6. Logistic regression analysis of predictors of non-uptake of VCT among undergraduates of tertiary institution.

\begin{tabular}{cccccc}
\hline & \multicolumn{2}{l}{$95 \%$ C.I for OR } & & & \\
\hline Variables & df & Sign & OR & Lower & Upper \\
\hline Ignorance & 1 & $0.001^{*}$ & 1.874 & 1.058 & 3.289 \\
Fear of positive result & 1 & $0.001^{*}$ & 2.455 & 1.308 & 4.608 \\
Stigma and discrimination & 1 & $0.001^{*}$ & 2.318 & 1.299 & 4.128 \\
People knowing HIV status & 1 & 0.441 & 1.082 & 0.889 & 1.324 \\
Distance from VCT site & 1 & 0.314 & 1.241 & 0.95 & 1.244 \\
\hline
\end{tabular}

*Statistically significant.

fear of positive result, stigma and discrimination, people knowing one's HIV status and distance from VCT site. Result showed that ignorance, fear of positive result, stigma and discrimination were important and positive predictors of 
non-uptake of VCT among undergraduates; OR 1.874 (1.058 - 3.289), P < 0.001 ; OR 2.455 (1.308 - 4.608), $\mathrm{P}<0.000$ and OR 2.318 (1.299 - 4.128), $\mathrm{P}<0.000$ respectively.

\section{Discussion}

This study showed that majority of the respondents generally had good knowledge of VCT for HIV with majority also knowing that it is voluntary. This finding is consistent with result from similar study among high school students in Ethiopia where the majority of the respondents were found to have adequate knowledge of VCT services [34].

It also agrees with other studies in Nigeria and Tanzania [17] [25] [35] which reported good knowledge about VCT among tertiary school students. This similarity might be due to exposure to VCT education among the students either in school or from other sources. The result from this study, however, is at variance with a community based study in China which reported a low level of knowledge about VCT for HIV [36]. This disparity in knowledge about VCT between this study and the report from the study in China could be accounted for by difference in the composition of the study population. A study by Fisher and colleagues [37] showed that difference in VCT-related knowledge among different subgroups appeared to be associated with VCT utilization, particularly in the lower social stratum. However, this association did not remain statistically significant after adjusting for stigma. Therefore, this indicates that the effect of knowledge on testing primarily worked through an effect on stigma. According to Fisher and colleagues, as cited by Kalichman and colleagues [37], fact-based education about HIV transmission is necessary, but not sufficient for promoting HIV testing.

The study found that majority of the respondents was aware of VCT and considered it necessary for the benefit of knowing their status. The findings are similar to a study conducted in Ethiopia in which a significant proportion of the respondents were found to be aware of the VCT services [34]. This finding might be due to the fact that many of the participants either lived in town or sub-Urban areas where sources of information like media and internet services are easily accessible.

According to this study, majority of the respondents had negative attitude towards VCT service. Only a few respondents would like to take VCT services themselves and recommend same to friends. This finding is disturbing in view of the strategic place of VCT in HIV prevention and control. This study finding agrees with a similar study which found that undergraduates of the University of Ilorin had a negative attitude towards HIV/AIDS VCT [38]. This finding also agrees with a study from Addis Ababa University [39]. The similarity of this study to the cited ones may be explained on the basis of similarities in study sites and population (university students). However, this finding is contrary to the findings from a study conducted in Ethiopia showed that majority of the res- 
pondents had positive attitude towards VCT services [40]. Majority of the respondents believed that undergoing VCT was of importance to all people; both HIVpositive and HIV-negative individuals benefit from the VCT results [41] [42].

Further, this finding is not in agreement with a result from a study carried out in Northern Nigeria which showed that majority of the adults volunteered to get VCT services and would recommend VCT to their friends [43]. This disparity could be due to the paucity of awareness about VCT and absence of VCT services in tertiary institutions contrary to the communities where efforts are expended on different strategies to scale up knowledge, attitude and availability of VCT services by both government and non-governmental organizations. The difference could also be attributed to the information available to the respondents in their study regarding the experience of HIV/AIDS patients. This difference in VCT utilization between tertiary institutions and the communities could probably also be attributed to differences in access to health care facilities offering HIV-testing and HIV/AIDS-related information. In Nigeria, as in other countries in sub-Saharan Africa, the distribution of health care facilities is uneven and skewed towards the communities [44].

Additionally, this study showed a high prevalence of non-uptake of VCT among the respondents. This result agrees with findings from similar studies conducted in tertiary institutions in Tanzania and Uganda [17] [45]. This agreement may be explained on the bases of similarities of the respondents' demographic characteristics and study sites. The studies were carried out in African Universities with about the same student demographics and knowledge about HIV. There may also be similarities in socio-psychological factors such as; one's health beliefs and health seeking behavior, cultural beliefs, social networks, perceived health status and severity of disease. The HIV epidemic is driven by this age group due largely to their low risk perception, low condom use and poor health seeking behaviour especially towards VCT services. According to sub-Saharan Africa survey, only $10 \%$ males and $15 \%$ females of 15 - 24 years had used VCT services, implying that majority of the young people in this age were undiagnosed from the HIV epidemic, thus exposing them to high risk of either acquiring or transmitting the disease [15].

One of the main predictors of non-uptake of VCT services identified in this study was ignorance of where to go for VCT. This finding is similar across different study areas including community-based surveys [28] [35] [46] [47]. It also agrees with other studies which showed that major barriers to uptake of VCT for HIV are associated with ignorance, fear of being positive, cost of VCT, inadequate number of VCT centers and stigmatization [17] [25] [26] [27] [28]. This similarity might be due to the fact that in Nigeria, as in other countries in sub-Saharan Africa, VCT education among undergraduates is not given priority enough to be included in the school curricula which will enable teachers and caregivers frequently talk about it in order to create awareness of its existence. With the absence of on-campus VCT centers, the frequency of visit to the center 
is absent, hence strengthening ignorance of where to go for VCT services.

A significant number of respondents reported fear of positive result as one of the main reasons for low VCT uptake. However, this may be due to lack of knowledge about support and care that may be available to them after positive VCT results. The findings are similar to a study conducted in Ethiopia, which found fear from anxiety and stress among the main factors influencing VCT uptake among the young people [34].

Further, this study identified stigma and discrimination as factors constituting a serious impediment for VCT uptake. A significant number of the study respondents admitted not taking up VCT services for fear of being stigmatized particularly when the result turned out positive. This finding is similar to results from other studies carried out in Nigeria and Ethiopia [37] [48]. This finding is also similar to a study conducted in Tanzania-Mwanza, where poor response to VCT was associated with fear of stigma [49] [50]. This finding also agrees with the one for a study done in Western Uganda, where a significant number of respondents reported fear from being stigmatized as being associated with low response to VCT [51]. A systematic review done by Mbonu et al. established a range of issues as discrimination in care, distancing and isolation as some of the barriers to VCT uptake in the sub-Saharan Africa [52]. In addition, Olagbuji and colleagues established that fear of stigmatization, break in relationship and spread of confidential information are the most important reasons for non-disclosure of status [53]. Yahaya et al. also found that discrimination and stigma as well as poverty and ignorance are some of the reasons for the low utilization of VCT in Kwara State of Nigeria [28].

This emphasizes the importance of creating greater awareness about HIV and the role of VCT in its prevention in order to allay fears associated with stigma and discrimination. This intervention relies on the competence of the counselors at the VCT centers. Further, contrary to expectation, the level of knowledge of VCT among the respondents in this study did not translate to equally good uptake of VCT thus, alluding to possible existence of other determinants of VCT uptake. However, there is need to improve the knowledge and attitude components of the barriers to uptake of VCT service.

The study also found distance to the VCT centre as one of the predictors of lack of decision towards VCT uptake. Among the reasons given included absence of VCT centre around their school premises, lack of knowledge about VCT and its location, lack of money to go for VCT as it involved some costs to reach the centre. Similarly, a study conducted in Tanzania-Mwanza, showed that long distance was associated with low VCT uptake among the students [54] [55]. Also a systematic review of published qualitative research in sub-Saharan Africa found that, direct and indirect costs were found to be associated with low uptake of VCT [56] [57].

\section{Limitation of the study}

This study was a cross-sectional survey data and by its nature, one of the limi- 
tations is the impossibility to draw causal conclusions. The information in the survey was self-reported, so some degree of under-reporting, over-reporting and bias arising from both recall and misunderstanding of questions were likely. This limitation was addressed by pre-testing the questionnaire to ensure sequencing and clarity of understanding. There was also the limitation of generalizability of the findings to other tertiary institutions as the study was a single institutional survey. There is need, therefore, for replication of the study in other institutions. The classification as knowledgeable and not knowledgeable based on a mean value should be interpreted in the context of this study, though the result offered information necessary for further study.

\section{Conclusions}

In conclusion, this study showed a high prevalence of non-uptake of VCT among the students. This has a dare consequence on the HIV prevalence among this age group. Voluntary counseling and testing has been recognized as an effective and important strategy for both prevention and care of HIV. The reasons for low uptake of VCT should be targeted and assessed so that a VCT enhancing intervention can be undertaken. If it is ignorance, which is a major issue, it becomes imperative that management of tertiary institutions strategically review and strengthen their VCT information, education and communication methods to enhance students' knowledge and awareness about VCT. Strategies that include integration of youth friendly VCT services in tertiary institutions would increase VCT uptake among the students.

For students afraid of positive result, the efficacy of formal institution-based VCT uptake education and counseling programmes needs evaluating. Pre-test counseling, post-test counseling and follow up should be skillfully conducted and support and care clearly communicated to the student after knowing the test results. This will help motivate more young people towards VCT uptake.

Stigma and discrimination is a major barrier to VCT uptake. The youthfriendly and medical centers of the University are veritable avenues for social marketing of VCT with all its potential benefits to the students. This will improve VCT uptake and reduce stigma among the students. Further, strengthening the communication between VCT clinics and other local community and health services is also an indispensable strategy for deepening awareness about VCT, mitigating stigma and enhancing uptake. Finally, the findings from this study will encourage policy makers holding the leavers of authority to enact law against stigmatizing and discriminating against people living with HIV.

From this study, a significant number had never seen a VCT center. Our findings therefore suggest that government initiatives will be needed to address the problem of geographical access to VCT services. Improving access to VCT by establishing more within the University and the environs will not only expose them to the service, but over time utilizing the service will become a culture.

The data from this study will also be useful to stakeholders and non-governmental 
organizations working on HIV/AIDS programs in designing appropriate, effective and specific interventions in tertiary institutions to address knowledge and attitude that might help to ensure greater uptake of VCT for HIV among the students.

\section{Acknowledgements}

I would like to thank the office assistants; A. Nwigwe and J. Agbara for their assistance in the production of this paper. I also thank my co-authors for contributing different sections of this paper and all authors whose works were cited in this work for their scholarly contribution to the body of knowledge.

\section{Conflicts of Interest}

The authors declare no conflicts of interest regarding the publication of this paper.

\section{References}

[1] Global HIV and AIDS Statistica-Fact Sheet 2020. https://www.unaids.org/en/resources/fact-sheet

[2] UNAIDS (2019) AIDSinfo.

[3] UNAIDS (2019) Communities at the Centre: Global AIDS Update 2019. p. 188.

[4] National Agency for the Control of AIDS (2019).

[5] Global Information and Education on HIV and AIDS. UNAIDS Data (2020).

[6] PEPFAR (2019) Large National Survey Shows Smaller HIV Epidemic in Nigeria than Once Thought and Highlights Key Gaps toward Reaching HIV Epidemic Control.

[7] UNAIDS (2017) Data Book, 2017.

[8] NACA (2015) Nigeria GARPR 2015.

[9] UNAIDS (2019) Report on the Global AIDS Epidemic: Executive Summary. UNAIDS, Geneva.

[10] Pharr, J.R., Enejoh, V., Mavegam, B.O., Olutola, A., Karick, H. and Ezeanolue, E.E. (2017) A Cross-Sectional Study of the Role of HIV/AIDS Knowledge in Risky Sexual Behaviors of Adolescents in Nigeria. International Journal of High Risk Behaviors and Addiction, 6, e63203. http://jhrba.com/en/articles/63203.html.Article https://doi.org/10.5812/ijhrba.63203

[11] National Bureau of Statistics (NBS) and United Nations Children's Fund (UNICEF) (2017) Multiple Indicator Cluster Survey 2016-17, Survey Findings Report.

[12] Jimoh, A.A.G. and Abubarkar, D. (2010) Antiretroviral Treatment in Africa: Problems and Prospects. Postgraduate Doctor-AFRICA, 25, 77-80.

[13] UNAIDS (2018) AIDSinfo.

[14] UNAIDS (2019) Communities at the Centre: Global AIDS Update. p. 191.

[15] WHO (2019) HIV and Adolescents Guidance for HIV Testing and Counseling and Care for Adolescents Living with HIV.

[16] NACA HIV Policy \& Advocacy Newsletter_Q1 (2018).

[17] Uzochukwu, B., Uguru, N., Ezeoke, U., Onwujekwe, O. and Sibeudu, T. (2011) Vo- 
luntary Counseling and Testing (VCT) for HIV/AIDS: A Study of the Knowledge, Awareness and Willingness to Pay for VCT among Students in Tertiary Institutions in Enugu State Nigeria. Health Policy, 90, 277-284. https://doi.org/10.1016/j.healthpol.2010.11.007

[18] Yahaya, L.A. (2014) Professionalization of Counselling in Nigeria. In: Idowu, A.I., (Ed.), Guidance and Counselling in Nigeria, Indemac Publications, Ilorin.

[19] Alao, S.A. (2017) Knowledge and Attitude towards HIV/AIDS among Students of Tertiary Institutions in Ilorin Metropolis. An M. Ed Project Submitted to the University of Ilorin Department of Guidance and Couselling.

[20] Pignatelli, S., Simpore, J., Pietra, V., Ouodraogo, G., Conombo, G. and Saeri, N. (2006) Factors Predicting Uptake of Voluntary Counselling and Testing in a Real-Life Setting in a Mother-and-Child Center in Ouagadougou, Burkina Faso. Tropical Medicine \& International Health, 11, 350-357. https://doi.org/10.1111/j.1365-3156.2006.01564.x

[21] Federal Ministry of Health, Ethiopia (2017) Guidelines for HIV Counseling and Testing in Ethiopia. Federal HIV/AIDS Prevention and Control Office.

[22] UNAIDS (2017) Data Book.

[23] Johns Hopkins School of Public Health (2016) Voluntary Counseling and Testing Rigorous Evidence-Usable Results.

[24] Global HIV Prevention Working Group (2013) Access to HIV Prevention-Closing the Gap. Kaiser Family Foundation, Menlo Park.

[25] Charles, P.M., Kweka, J.E., Mahande, M.A., Barongo, R.L., Shekalaghe, S., Nkya, M.H., et al. (2019) Evaluation of Uptake and Attitude to Voluntary Counseling and Testing among Health Care Professional Students in Kilimanjaro Region, Tanzania. BMC Public Health, 9, Article No. 128. https://doi.org/10.1186/1471-2458-9-128

[26] Li, X., Lin, C., Gao, Z., Stanton, B., Fang, X., Yin, Q. and Wu, Y. (2014) HIV/AIDS Knowledge and the Implications for Health Promotion Programs among Chinese College Students: Geographic, Gender and Age Differences. Health Promotion International, 19, 345-356. https://doi.org/10.1093/heapro/dah308

[27] Shankar, P.R., Subish, P., Paudel, R. and Alam, K. (2009) Perception and Knowledge about HIV/AIDS among Students in a Medical College in Western Nepal. SAARC Journal of Tuberculosis, Lung Diseases and HIVI AIDS, 2, 11-16. https://doi.org/10.3126/saarctb.v6i2.3052

[28] Yahaya, L.A., Jimoh, A.A.G. and Balogun, O.R. (2010) Factors Hindering Acceptance of HIV/AIDS Voluntary Counseling and Testing (VCT) among Youth in Kwara State, Nigeria. African Journal of Reproductive Health, 14, 159-164.

[29] NACA (2017) National Strategic Framework 2017-2021.

[30] Duncan, C., Miller, D.M. and Borskey, E.J. (2012) Barriers to Safer Sex Practices among African American College Students. Journal of the National Medical Association, 94, 944-951.

[31] Prince, A. and Bernard, A.L. (2009) Sexual Behaviors and Safer Sex Practices of College Students at a Commuter Campus. Journal of American College Health, 47, 11-21. https://doi.org/10.1080/07448489809595614

[32] Lewis, J.E., Malow, R.M. and Ireland, S.J. (2008) HIV/AIDS Risk in Heterosexual College Students-A Review of a Decade of Literature. Journal of American College Health, 45, 147-158. https://doi.org/10.1080/07448481.1997.9936875

[33] WHO/UNAIDS/UNICEF (2019) Report on the Global HIV/AIDS Epidemic. WHO, Geneva. 
[34] Gatta, A.A. (2011) Knowledge and Attitudes towards Voluntary HIV Counseling and Testing Services amongst Adolescent High School Students in Addis Ababa Ethiopia. AOSIS Open Journal, 35, 103-108. https://doi.org/10.4102/curationis.v35i1.103

[35] Daniyam, C.A., Agaba, P.A. and Agaba, E. (2010) Acceptability of Voluntary Counseling and Testing among Medical Students in Jos, Nigeria. Journal of Infection in Developing Countries, 4, 357-361. https://doi.org/10.3855/jidc.683

[36] Ma, W., Detels, R., Feng, Y., Wu, Z., Shen, L., Li, Y., et al. (2007) Acceptance of and Barriers to Voluntary HIV Counselling and Testing among Adults in Guizhou Province, China. AIDS, 21, 129-135.

https://doi.org/10.1097/01.aids.0000304708.64294.3f

[37] Kalichman, S.C. and Simbayi, L.C. (2013) HIV Testing Attitudes, AIDS Stigma, and Voluntary HIV Counselling and Testing in a Black Township in Cape Town, South Africa. Sexually Transmitted Infections, 79, 442-447.

https://doi.org/10.1136/sti.79.6.442

[38] Okpoto, R.I. (2009) Attitude of University of Ilorin Undergraduates towards Voluntary HIV/AIDS Counselling and Testing. An unpublished B.Ed Project Submitted to the Department of Counsellor Education, University of Ilorin, Ilorin.

[39] Regassa, N. and Kedir, S. (2011) Attitudes and Practices on HIV Preventions among Students of Higher Education Institutions in Ethiopia: The Case of Addis Ababa University. East African Journal of Public Health, 8, 141-154.

[40] Tewabe, T., Destaw, B., Admassu, M. and Abera, B. (2012) Assessment of Factors Associated with Voluntary Counselling and Testing Uptake among Students in Bahir Dar University Ethiopia. Ethiopian Journal of Health Development, 26, 16-21.

[41] Baisley, K.., Doyle, A.M., Changalucha, J., Maganja, K.., Watson-Jones, D., Hayes, R. and Ross, D. (2012) Uptake of Voluntary Counselling and Testing among Young People Participating in an HIV Prevention Trial: Comparison of Opt-Out and Opt-In Strategies. PLoS ONE, 7, e42108. https://doi.org/10.1371/journal.pone.0042108

[42] Pikard, J.L. (2009) HIV Voluntary Counselling and Testing among Kenyan Male Youth Aged 13-15 Years: The Theory of Planned Behaviour Applied. Masters Abstracts International, 49, 42.

[43] Lliyasu, Z., Abubakar, S.I., Kabir, M. and Aliyu, H.M. (2006) Knowledge of HIV/ AIDS and Attitude towards Voluntary Counseling and Testing among Adults. Journal of the National Medical Association, 98, 1912-1922.

[44] Kloos, H. and Mariam, D.H. (2010) HIV/AIDS in Ethiopia: An Overview. Northeast African Studies, 7, 13-40. https://doi.org/10.1353/nas.2004.0006

[45] Vermeer, W., Bos, E.R.A., Mbwamboc, J., Kaaya, S. and Schaalma, P.H. (2009) Social and Cognitive Variables Predicting Voluntary HIV Counseling and Testing among Tanzanian Medical Students. Patient Education and Counseling, 75, 135-140. https://doi.org/10.1016/j.pec.2008.08.022

[46] Peltzer, K., Mpofu, E., Baguma, P. and Lawal, B. (2002) Attitudes towards HIV-Antibody Testing among University Students in Four African Countries. International Journal for the Advancement of Counselling, 24, 193-203. https://doi.org/10.1023/A:1022991522264

[47] Meiberg, A.E., Bos, E.R.A., Onya, E.H. and Schaalma, P.H. (2008) Fear of Stigmatization as Barrier to Voluntary HIV Counselling and Testing in South Africa. East African Journal of Public Health, 5, 49-54.

[48] Muoghalu, C.O. and Jegede, S.A. (2010) The Role of Cultural Practices and the 
Family in the Care for People Living with HIV/AIDS among the Igbo of Anambra State, Nigeria. Social Work in Health Care, 49, 981-1006.

https://doi.org/10.1080/00981389.2010.518885

[49] Wringe, A., Isidingo, R., Urassa, M., Todd, J., Mbata, D., Maiseli, G., et al. (2007) Trends in Uptake of Voluntary Counseling and Testing for HIV in Rural Tanzania under Widely Provision of HIV Treatments. Tropical Medicine and International Health, 17, e15-e25.

[50] Kakoko, D.C.V. (2006) Voluntary HIV Counseling and Testing Service Uptake among Primary School Teachers in Mwanza-Tanzania. AIDS Care, 18, 554-560.

[51] Bwambale, M.F., Ssali, N.S., Byaruhanga, S., Kalyango, J.N. and Karamagi, C.A.S. (2008) Voluntary HIV Counselling and Testing among Men in Rural Western Uganda: Implications for HIV Prevention. BMC Public Health, 8, Article No. 263. https://doi.org/10.1186/1471-2458-8-263

[52] Mbonu, N.C., van den Borne, B. and De Vries, N.K. (2009) Stigma of People with HIV/AIDS in Sub-Saharan Africa: A Literature Review. Journal of Tropical Medicine, 2009, Article ID: 145891. https://doi.org/10.1155/2009/145891

[53] Olagbuji, B.N., Ezeanochie, M.C., Agholor, K.N., Olagbuji, Y.W., Ande, A.B. and Okonofua, F.E. (2011) Spousal Disclosure of HIV Serostatus among Women Attending Antenatal Care in Urban Nigeria. Journal of Obstetrics and Gynaecology, 31, 486-488. https://doi.org/10.3109/01443615.2011.563637

[54] Ministry of Health and Social Welfare Tanzania (2012) National Guideline for the Management of HIV and AIDS.

[55] Sukari, O. (2007) Barriers and Attitudes towards HIV Voluntary Counseling and Testing among Secondary School Pupils of Sengerema in Mwanza. Dar Es Salaam Medical Students' Journal, 15, 20-23.

[56] Musheke, M., Ntalasha, H., Gari, S., Mckenzie, O., Bond, V., Martin-Hilber, A. and Merten, S. (2013) A Systematic Review of Qualitative Findings on Factors Enabling and Deterring Uptake of HIV Testing in Sub-Saharan Africa. BMC Public Health, 13, Article No. 220. https://doi.org/10.1186/1471-2458-13-220

[57] Medical Research Council (2018) A Review of Research among Black African Communities Affected by HIV in the UK and Europe. http://www.sphsu.mrc.ac.uk/library/occasional/OP015.pdf 